\title{
Does health literacy affect the uptake of annual physical check-ups?: Results from the 2017 US health information national trends survey
}

Hee Yun Lee ${ }^{1}$, Sooyoung Kim² ${ }^{2}$, Jessica Neese ${ }^{1}$ and Mi Hwa Lee ${ }^{3}$

\begin{abstract}
Background: Little is known about how health literacy is linked to physical check-ups. This study aimed to examine the levels of physical check-ups (self-reported check-ups within the last year) by age group (those aged 18-59 years and those aged $=\geq 60$ years) and the role of health literacy regarding physical check-ups in the United States.

Methods: Data for the study were obtained from the 2017 Health Information National Trends Survey. The original sample included 3,285 respondents, but only 3,146 surveys were used for this study. Andersen's Behavioral Model of Health Services Use guided this study, and a binomial logistic regression model was conducted using Stata 12.0 software package.

Results: While $82.0 \%$ of the older group had an annual check-up, $67.3 \%$ of the younger group had one. Both groups had similar ratios for health literacy-related item reporting. Study results show that annual check-up was positively associated with confidence in getting health information, having health insurance, and having a primary doctor for both age groups. However, getting a regular check-up was negatively associated with frustration while searching for information among the younger group. In comparison, it was positively associated with difficulty understanding information for the older group.

Conclusions: To increase annual physical check-ups, health literacy-related interventions should be developed and address the barriers most associated with health check-ups. One way of addressing this barrier is to improve communication from healthcare professionals to consumers through the use of easy-to-understand explanations appropriate for the consumer.
\end{abstract}

Keywords: Health literacy, Physical check-ups, Older adults, Young adults, Andersen behavioral model

\section{Background}

Routine physical check-ups offer multiple health benefits that can lead to a longer, healthier life. Regular check-ups, defined as a routine test primary care provider performs to check overall health, are used to assess individuals'

\footnotetext{
* Correspondence: kimsy@cup.ac.kr

${ }^{2}$ Dept. of Aging and Social Work, College of Nursing, Catholic University of Pusan, Busan, South Korea

Full list of author information is available at the end of the article
}

general health and prevent future illnesses [1]. Check-ups give health care providers an opportunity to get to know their patients better [2], allow for early detection of health problems in the beginning or early stages and offer better treatment chances [3, 4], and can be cost-saving [4]. Despite the benefits of regular check-ups, some argue there is no clear evidence to support the need for physical checkups [5], while others believe that annual check-ups increase diagnoses and medications but does not affect ways

(C) The Author(s). 2021 Open Access This article is licensed under a Creative Commons Attribution 4.0 International License, which permits use, sharing, adaptation, distribution and reproduction in any medium or format, as long as you give appropriate credit to the original author(s) and the source, provide a link to the Creative Commons licence, and indicate if changes were made. The images or other third party material in this article are included in the article's Creative Commons licence, unless indicated otherwise in a credit line to the material. If material is not included in the article's Creative Commons licence and your intended use is not permitted by statutory regulation or exceeds the permitted use, you will need to obtain permission directly from the copyright holder. To view a copy of this licence, visit http://creativecommons.org/licenses/by/4.0/. The Creative Commons Public Domain Dedication waiver (http://creativecommons.org/publicdomain/zero/1.0/) applies to the data made available in this article, unless otherwise stated in a credit line to the data. 
to decrease morbidity and mortality from diseases such as cardiovascular issues and cancer [2]. Contrary to critics' arguments, physical check ups are still needed to continue identifying and detecting diseases and other health issues that individuals experience early [6]. By being at the forefront of these diseases and issues, physicians can provide individuals with the appropriate services or referal as needed and reduce patients' concerns [1].

Previous studies have reported various barriers and facilitators associated with regular check-ups, including socio-demographic characteristics (e.g., age, gender, income) [7-9], accessibility to health care services (e.g., health insurance, primary doctor, and living area) [10$13]$, personal cancer history [14, 15], and family cancer history [16]. For instance, individuals in rural areas were less likely to have physical check-ups because obtaining a primary care doctor was difficult as physicians are typically in cities and more affluent suburbs, and having low income was associated with not seeing a doctor for check-ups because of cost [17]. On the other hand, young adults between the ages of 18-26 with a usual source of care were more likely to utilize physical checkups [18], and having health insurance increased the likelihood of routine check-ups [13]. Another facilitating factor includes having a history of physical check-ups. Labeit and colleagues [4] concluded that individuals who visited a general physician in the past year were more likely to make an appointment for the coming year, suggesting that once the behavior of annual check-ups is initiated, the behavior will continue. Interestingly, individuals with a history of cancer were more likely to utilize check-ups than those without a history $[14,15]$, but having a family history of cancer did not increase one's routine check-ups use [16].

In addition to the literature supporting factors associated with physical check-ups, health literacy could be another critical factor to explain an individual's physical check-ups $[19,20]$. For example, people with limited health literacy tend to have cancer screenings and immunizations less frequently [21]. However, little is known about how health literacy is linked to physical check-ups. To our best knowledge, this is the first study to investigate the contribution of health literacy to the uptake of physical check-ups.

Moreover, previous studies showed that age was a significant factor that was relevant for the utilization of check-ups [22, 23]. Other studies also reported that over 60 years old age showed significant health problems when compared to different age groups [24-26]. It will be very crucial to investigate the differences in uptakes of check-ups by age groups.

Hence, this study aimed to examine the levels of physical check-up uptake and factors associated with physical check-ups with specific attention to health literacy's role on physical check-up uptake in two age groups. In our study, health literacy was defined as an individuals' ability to obtain, process, and understand basic health information to make responsible decisions regarding their health $[27,28]$.

\section{Conceptual framework}

The Andersen's Behavioral Model of Health Services Use [29] guided this study. The Andersen's Behavioral Model has been used extensively to examine relationships between predisposing, enabling, and need factors and health service utilization [22, 23, 30,31]. The Andersen model is commonly used in studies on various health services divisions and diseases, such as HIV, dental, and long-term care [32-34]. The model has also been used to predict variables associated with health literacy $[30,31,35]$.

According to the Andersen model, individuals' access to and use of health services are explained by three components of predisposing, enabling, and need factors [29]. The model purports that health service utilization is dependent on individuals' propensity to use services (predisposing), their ability to access services (enabling), and their illness level (need) [22]. The model believes that three types of individual factors facilitate or impede access to and utilize health care services [23]. Predisposing factors identified in health care settings include sociodemographic determinants such as age, gender, marital status, socioeconomic status (SES), and family status [22, 23, 30]. Enabling factors include education, primary care physicians, health insurance coverage, availability of health services, and social support [22, 23, 30]. Need factors include medical conditions and depression/anxiety [22].

As predisposing factors according to the Andersen model, we consider age, gender, income, and living area which has individual's social-cultural characteristics. As enabling factors according to the Andersen model, health literacy, education, health insurance, and primary doctor, which reflect conditions making healthcare available to individuals, were considered. Need factors include an individual's beliefs on their health and access to services such as self-reported health and the number of diseases (e.g., chronic disease, depression, cancer, etc.) and personal and family history of cancer. Figure 1shows the conceptual model of this study.

\section{Methods}

Data and sample

The current study's data is derived from the US-based 2017 Health Information National Trends Survey (HINT S). The National Cancer Institute administers the HINT $\mathrm{S}$ program to assess the American's health information 


\begin{tabular}{|l|}
\hline Independent Variables \\
\hline Predisposing Factors \\
\hline - Age \\
- Gender \\
- Income \\
- Living Area (Rural vs Urban) \\
\hline Enabling Factors \\
\hline - Health Literacy \\
- Education \\
- Health Insurance \\
- Primary Doctor \\
\hline Need Factors \\
\hline - Health Status \\
- Chronic Disease \\
- Depression \\
- Personal History of Cancer \\
- Family History of Cancer \\
\hline
\end{tabular}

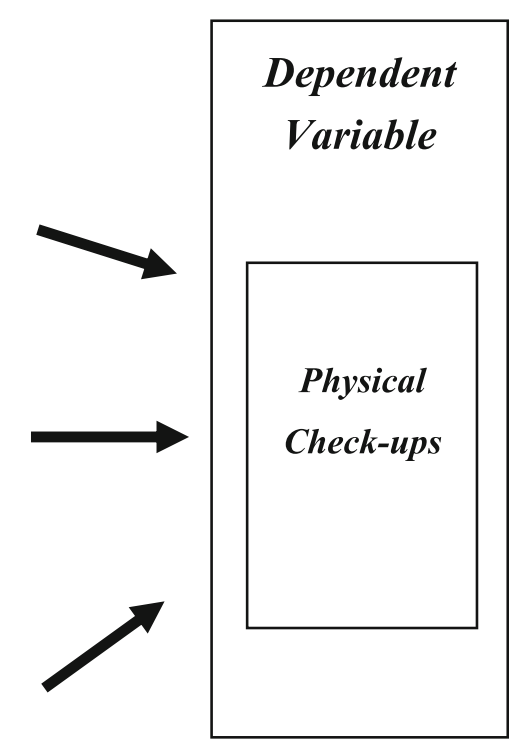

Fig. 1 Conceptual Framework of uptake of physical check-ups in the United States

use and health behavior. Briefly, a single-mode mail survey was generated and dispersed from January to May 2017. HINTS was administered in two languages, English and Spanish. The original sample included 3,285 respondents, but our study sample included 3,146. To achieve the present study's objectives, we excluded those aged under 18 years $(\mathrm{N}=139)$. The sample was categorized into two subgroups: those aged 18-59 years and those aged $=\geq 60$ years. Since World Health Organization (WHO) suggested that most developed countries characterize old age starting and 60 years and above [36].

Overall, the sample consisted of 1,681 respondents aged 18-59 years and 1,465 respondents aged $=\geq 60$ years.

\section{Measures \\ Dependent variables}

The dependent variable measured respondents' selfreported check-ups within the last year $(1=$ Yes, $0=$ No). The routine check-ups meant a general physical exam. It did not include an exam for a specific injury, illness, or condition.

\section{Independent Variables}

Three sets of independent variables were included, representing the Andersen model's predisposing, enabling, and need factors.

(1) Predisposing factors: Four predisposing factors included age, gender $($ male $=0$; female $=1)$, income, and living area (rural $=0$; urban $=1$ ). Income was measured with nine categories $(1=\$ 0-9,999 ; 2=$ $\$ 10,000-14,999 ; 3=\$ 15,000-19,999 ; 4=\$ 20,000-$ 34,$999 ; 5=\$ 35,000-49,999 ; 6=\$ 50,000-74,999 ; 7$ $=\$ 75,000-99,999 ; 8=\$ 100,000-199,999 ; 9$ $=\geq \$ 200,000$ ). But collapsed into two groups (less than $\$ 74,999=0 ; \$ 75,000$ or more $=1$ ) only for descriptive statistics. Living area was measured as rural or urban and the areas were defined by the 2013 Rural-Urban Continuum Codes.

(2) Enabling Factors. Four enabling factors included health literacy, education, health insurance, and primary doctor. Health literacy was measured using five items: (1) it took great effort to get the information you need, (2) you felt frustrated during your search for information, (3) you were concerned about the quality of the information you found, (4) the information you found was hard to understand, and (5) confidence in getting health information. The first four items are based on a 4point scale ranging from strongly disagree (1), disagree (2), agree (3), and to strongly agree (4). For analysis, all items were dichotomized ( 0 = disagree; $1=$ agree). The last health literacy item (confidence in getting health information) was measured on a 5point scale from not confident at all (1), a little confident (2), somewhat confident (3), very confident (4), and to completely confident (5). For descriptive analysis, it was dichotomized as not very confident (0) or very confident (1). The internal consistency (Cronbach's $\alpha$ ) of the five items in the full sample 
was 0.911 . Education was measured by seven categories $(1=$ less than eight years; $2=$ eight through 11 years; $3=12$ years or completed high school; $4=$ post-high school training other than college; $5=$ some college; 6 = college graduate; 7 = postgraduate) and the level of education was dichotomized as under some college (0) or some college and above (1) for descriptive analysis. The two variables of health insurance and primary doctors were measured using a yes (1) or no (0) question.

(3) Need Factors. Five need factors consisted of selfrated health status, chronic disease, depression, personal history of cancer, and family history of cancer. Health status was measured by a single question on a five-scale from poor (1) to excellent (5). Chronic disease was measured using five items: (1) Diabetes or high blood sugar (2) High blood pressure or hypertension (3) A heart condition such as heart attack, angina, or congestive heart failure (4) Chronic lung disease, asthma, emphysema, or chronic bronchitis (5) Arthritis or rheumatism. These items were measured using a yes (1) or no (0) question and the total score was computed by summing five items. Depression was measured using the four-item Patient Health Questionnaire (PHQ-4) (i.e., little interest or pleasure in doing things; feeling down, depressed, or hopeless; feeling nervous, anxious, or on edge; not being able to stop or control worrying). All the items were on a four-scale from not at all (1) to nearly every day (4), with a higher score indicating a high level of depression. The total score was computed by summing four individual items. The sum of each variable ranged from 4 to 16. The internal consistency (Cronbach's $\alpha$ ) of the four items in the full sample was 0.942. Two questions of cancer history were measured if the respondent has cancer (yes $=1 ; n o=0)$ and if their family has cancer (yes $=1 ; n o=0)$.

\section{Data analysis}

Our analytic process involved two steps. In step one, descriptive statistics were calculated to generate frequencies and proportions for sociodemographic characteristics of the sample and the health literacy and check-up variables. These statistics were calculated by younger and older age groups. Differences between younger and older respondents were examined using $x 2$ tests with an $\alpha$ level of 0.05 . In the second step, to examine health literacy's role on a physical check-up uptake among study samples, we used a binomial logistic regression model with adjustments for predisposing factors, enabling factors, and need factors. All analyses applied jackknife weighting procedures provided by HINTS for analysis of the intricate survey design and were conducted using survey procedures in Stata version 12.0 [37]. This way allowed us to produce a valid variance estimation that eventually led us to produce unbiased estimates.

\section{Results \\ Sociodemographic Characteristics}

Table 1 presents the sociodemographic characteristics by age group. Of the 1,681 respondents in the 18-59 age group, $67.3 \%$ had an annual check-up within the past year and $82.0 \%$ of the 1,465 respondents in the 60 years or older group. The average age was 44 years $(\mathrm{SD}=$ $10.737)$ in the younger group and 70 years $(S D=7.999)$ in the older group. There were relatively more females than males in both age groups. About $56.41 \%$ of the younger group and $72.42 \%$ of the older group members earned $<\$ 75,000$ per year. Most $(88.58 \%$ and $84.37 \%$, respectively) participants lived in an urban area. Two-fifths of the younger group completed some college or higher, and nearly half $(41.18 \%)$ of the older group had a high school diploma or less. The majority in both groups had health insurance. More than a third in the younger group and most $(81 \%)$ of the older group had a primary doctor, and $86.1 \%$ of the younger and $77.79 \%$ of the older group reported their health as more than good. The average number of chronic diseases was higher in the older group $(1.613, \mathrm{SD}=1.178)$ than the younger group $(0.763, \mathrm{SD}=1.009)$. The average depression level was higher in the younger group $(6.069, \mathrm{SD}=2.923)$ than the older group $(5.747, \mathrm{SD}=2.617$ ). Only $7.74 \%$ had ever had cancer in the younger group and $24.16 \%$ in the older group.

Second, the younger and older groups had similar ratios for health literacy-related item reporting. Nearly a third put forth a lot of effort to get information $(32.06 \%$, $38.84 \%)$ and felt frustrated during searches for information $(31.05 \%, 33.3 \%)$. About a fourth $(21.25 \%, 28.55 \%)$ reported that understanding the information they had found was difficult, yet almost $60 \%$ of respondents in both groups $(63.7 \%, 59.38 \%)$ reported that they felt confident getting health information.

Lastly, as can be seen by the cross-tabulated frequencies in Table 1, there were significant relationships between health insurance $\left(x^{2}=35.753, p<.000, \chi^{2}=11.950\right.$, $p<.000)$, primary doctor $\left(\chi^{2}=129.341, p<.000, \chi^{2}=\right.$ $57.508, p<.000)$, confidence in getting health information $\left(\chi^{2}=8.142, p<.01, \chi^{2}=5.343, p<.5\right)$ and uptake of check-ups for both age groups and gender $\left(x^{2}=8.383\right.$, $p<.01)$, income $\left(\mathrm{x}^{2}=4.697, p<.05\right)$, great effort required to get information $\left(\chi^{2}=8.841, p<.05\right)$, frustration while searching for information $\left(x^{2}=16.449, p<.000\right)$, concerns about the quality of retrieved information $\left(x^{2}=\right.$ $4.962, p<.05)$ and uptake of check-ups among the younger group. 
Table 1 Estimates for Sociodemographic and check-ups by Age Groups in the United States, the 2017 US Health Information National Trends Survey

\begin{tabular}{|c|c|c|c|c|c|c|c|c|}
\hline \multirow{4}{*}{ Variables } & \multirow{4}{*}{$\begin{array}{l}\begin{array}{l}\text { Frequency } \\
\text { (Mean/Number) }\end{array} \\
\text { Mean } \\
\text { (S.D.) /Total(\%) }\end{array}$} & \multirow{2}{*}{\multicolumn{3}{|c|}{$\begin{array}{l}\text { Check-ups } \\
\text { Age between } 18 \text { and } 59\end{array}$}} & \multirow{4}{*}{$\begin{array}{l}\begin{array}{l}\text { Frequency } \\
\text { (Mean/Number) }\end{array} \\
\text { Age } 60 \text { and Over } \\
\text { Mean } \\
\text { (S.D.) /Total(\%) }\end{array}$} & \multicolumn{3}{|c|}{ Check-ups } \\
\hline & & & & & & & & \\
\hline & & No & Yes & $x^{2}$ & & No & Yes & $x^{2}$ \\
\hline & & $\%$ & $\%$ & & & $\%$ & $\%$ & \\
\hline \multicolumn{9}{|l|}{ Dependent Variable } \\
\hline Check-up & $0.673(0.469)$ & 32.75 & 67.25 & & $0.820(384)$ & 18.02 & 81.98 & \\
\hline \multicolumn{9}{|l|}{ Predisposing factor } \\
\hline Age & $44(10.737)$ & & & & 70(7.999) & & & \\
\hline \multicolumn{9}{|l|}{ Gender } \\
\hline Male & $665(39.82)$ & 36.84 & 63.16 & $8.3826^{* *}$ & $598(41.61)$ & 19.40 & 80.60 & 1.4497 \\
\hline Female & $1,005(60.18)$ & 30.05 & 69.95 & & 839(58.39) & 16.92 & 83.08 & \\
\hline \multicolumn{9}{|l|}{ Income } \\
\hline$\$ 0$ to $\$ 74,999$ & $898(56.41)$ & 34.97 & 65.03 & $4.697^{*}$ & $927(72.42)$ & 18.12 & 81.88 & 0.904 \\
\hline$\$ 75,000$ or more & 694(43.59) & 29.83 & 70.17 & & $353(27.58)$ & 15.86 & 84.14 & \\
\hline \multicolumn{9}{|l|}{ Living Area } \\
\hline Urban & $1,489(88.58)$ & 32.84 & 67.16 & 0.089 & $1,236(84.37)$ & 18.28 & 81.72 & 0.374 \\
\hline Rural & 192(11.42) & 31.77 & 68.23 & & $229(15.63)$ & 16.59 & 83.41 & \\
\hline \multicolumn{9}{|l|}{ Enabling Factors } \\
\hline \multicolumn{9}{|l|}{ A lot of Effort to get the information } \\
\hline Agree & $436(32.06)$ & 37.84 & 62.16 & $8.841^{* *}$ & $430(38.84)$ & 16.74 & 83.26 & 0.011 \\
\hline Disagree & $924(67.94)$ & 29.76 & 70.24 & & $677(61.16)$ & 16.99 & 83.01 & \\
\hline \multicolumn{9}{|c|}{ Frustrated during search for the information } \\
\hline Agree & $422(31.05)$ & 40.05 & 59.95 & $16.449^{* * *}$ & $360(33.30)$ & 18.61 & 81.39 & 1.214 \\
\hline Disagree & $937(68.95)$ & 28.92 & 71.08 & & $721(66.70)$ & 15.95 & 84.05 & \\
\hline \multicolumn{9}{|l|}{$\begin{array}{l}\text { Concerned about the quality } \\
\text { of the information }\end{array}$} \\
\hline Agree & $731(53.83)$ & 35.02 & 64.98 & $4.962^{*}$ & $485(44.58)$ & 16.49 & 83.51 & 0.066 \\
\hline Disagree & $627(46.17)$ & 29.35 & 70.65 & & $603(55.42)$ & 17.08 & 82.92 & \\
\hline \multicolumn{9}{|c|}{ Information you found was hard to understand } \\
\hline Agree & $288(21.25)$ & 34.03 & 65.97 & 0.485 & $312(28.55)$ & 16.99 & 83.01 & 0.007 \\
\hline Disagree & $1,067(78.75)$ & 31.87 & 68.13 & & $781(71.45)$ & 16.77 & 83.23 & \\
\hline \multicolumn{9}{|l|}{ Confident get Health information } \\
\hline Very confident & $1,046(63.70)$ & 30.21 & 69.79 & $8.142^{* *}$ & $842(59.38)$ & 16.03 & 83.97 & $5.343^{*}$ \\
\hline Not very confident & $596(36.30)$ & 37.08 & 62.92 & & $576(40.62)$ & 20.83 & 79.17 & \\
\hline \multicolumn{9}{|l|}{ Education } \\
\hline High school deploma or less & $433(25.88)$ & 36.26 & 63.74 & 3.370 & $598(41.18)$ & 17.56 & 82.44 & 0.211 \\
\hline Completed some college or higher & $1,240(74.12)$ & 31.45 & 68.55 & & $854(58.82)$ & 18.50 & 81.50 & \\
\hline \multicolumn{9}{|l|}{ Health Insurance } \\
\hline Yes & $1,560(93.41)$ & 30.58 & 69.42 & $35.753^{* * *}$ & $1,411(97.51)$ & 16.80 & 83.20 & $11.950^{* * *}$ \\
\hline No & $110(6.59)$ & 58.18 & 41.82 & & $36(2.49)$ & 38.89 & 61.11 & \\
\hline \multicolumn{9}{|l|}{ Primary doctor } \\
\hline Yes & $1,072(64.19)$ & 22.67 & 77.33 & $129.341^{* * *}$ & $1,173(81.01)$ & 13.55 & 86.45 & $57.508^{* * *}$ \\
\hline No & $598(35.81)$ & 49.83 & 50.17 & & 275(18.99) & 32.73 & 67.27 & \\
\hline
\end{tabular}


Table 1 Estimates for Sociodemographic and check-ups by Age Groups in the United States, the 2017 US Health Information National Trends Survey (Continued)

\begin{tabular}{|c|c|c|c|c|c|c|c|c|}
\hline \multirow{4}{*}{ Variables } & \multirow{4}{*}{$\begin{array}{l}\begin{array}{l}\text { Frequency } \\
\text { (Mean/Number) }\end{array} \\
\text { Mean } \\
\text { (S.D.) /Total(\%) }\end{array}$} & \multicolumn{3}{|c|}{ Check-ups } & \multirow{4}{*}{$\begin{array}{l}\begin{array}{l}\text { Frequency } \\
\text { (Mean/Number) }\end{array} \\
\text { Age } 60 \text { and Over } \\
\text { Mean } \\
\text { (S.D.) /Total(\%) }\end{array}$} & \multicolumn{3}{|c|}{ Check-ups } \\
\hline & & \multicolumn{3}{|c|}{ Age between 18 and 59} & & & \multirow{3}{*}{$\begin{array}{l}\text { Yes } \\
\%\end{array}$} & \\
\hline & & No & Yes & $x^{2}$ & & \multirow{2}{*}{$\begin{array}{l}\text { No } \\
\%\end{array}$} & & \multirow[t]{2}{*}{$x^{2}$} \\
\hline & & $\%$ & $\%$ & & & & & \\
\hline \multicolumn{9}{|l|}{ Need factors } \\
\hline \multicolumn{9}{|l|}{ Health Status } \\
\hline More than Good & $1,437(86.10)$ & 33.54 & 66.46 & 2.767 & 1,131(77.79) & 17.95 & 82.05 & 0.017 \\
\hline Less than Fair & $232(13.90)$ & 28.02 & 71.98 & & $323(22.21)$ & 18.27 & 81.73 & \\
\hline Chronic Diseases & $0.763(1.009)$ & & & & $1.613(1.178)$ & & & \\
\hline Depression & $6.069(2.923)$ & & & & $5.747(2.617)$ & & & \\
\hline \multicolumn{9}{|c|}{ Personal History of Cancer } \\
\hline Yes & 130(7.74) & 33.23 & 66.77 & 2.164 & $353(24.16)$ & 16.71 & 83.29 & 0.578 \\
\hline No & $1,550(92.26)$ & 26.92 & 73.08 & & $1,108(75.84)$ & 18.50 & 81.50 & \\
\hline \multicolumn{9}{|c|}{ Family History of Cancer } \\
\hline Yes & $1,153(73.49)$ & 31.74 & 68.26 & 0.799 & $1,069(77.02)$ & 17.40 & 82.60 & 0.499 \\
\hline No & $416(26.51)$ & 34.13 & 65.87 & & $319(22.98)$ & 19.12 & 80.88 & \\
\hline
\end{tabular}

Note: ${ }^{*} \boldsymbol{p}<.05 ;{ }^{* *} \boldsymbol{p}<.01,{ }^{* * *} \boldsymbol{p}<.001$

\section{Factors associated with Physical Check-ups}

Estimates from the binominal logistic regression model presented in Table 2 show that annual check-up associated positively with health insurance $(\mathrm{OR}=2.576,95 \%$ $\mathrm{CI}=1.612-4.118, \quad \mathrm{OR}=2.341, \quad 95 \% \mathrm{CI}=1.024-5.352)$, primary doctor $(\mathrm{OR}=2.636,95 \% \mathrm{CI}=2.065-3.363$, $\mathrm{OR}=2.361,95 \% \mathrm{CI}=1.658-3.363)$ and chronic disease $(\mathrm{OR}=1.435,95 \% \mathrm{CI}=1.235-1.668, \quad \mathrm{OR}=1.438,95 \%$ $\mathrm{CI}=1.228-1.685)$ for both age groups. However, the dependent variable was negatively associated with frustration while searching for information $(\mathrm{OR}=0.758$, $95 \% \mathrm{CI}=0.617-0.933)$ and positively associated with age $(\mathrm{OR}=1.016,95 \% \mathrm{CI}=1.004-1.029)$, gender $(\mathrm{OR}=$ 1.377, $95 \% \mathrm{CI}=1.084-1.751)$ and confidence getting health information ( $\mathrm{OR}=1.154,95 \% \mathrm{CI}=1.000-1.332)$ among the younger group and positively associated with the term information you found was hard to understand $(\mathrm{OR}=1.428,95 \% \mathrm{CI}=1.069-1.909)$ for the older group.

\section{Discussion}

Guided by Andersen's Behavioral Model, the current study examined the levels of physical check-ups and factors associated with physical check-ups with a specific focus on the role of health literacy in the uptake of physical check-ups in two age groups. Of the older group participants, $82 \%$ reported an annual check-up within the last year, while only $67.3 \%$ of the younger group reported the same. Our findings are consistent with previous studies that the older group received more physical check-ups than younger adults [7, 38-40]. Among the
Korean participants of a similar study, $29.5 \%$ of the older age group regularly visited the doctor, and only $8 \%$ of the younger group reported regular visits, further proving that older adults utilize regular visits to the doctor more than younger adults [40]. It might be a rational assumption that older adults take action as the onset of adverse health issues arise rather than waiting like younger generations who are less likely to experience health issues and have a positive perception about their health.

The results from binominal logistic regression analysis indicated that two predisposing factors (age and gender) in the younger group and three enabling factors (health literacy, health insurance, and primary doctor) and one need factor (chronic disease) in both age groups were significant factors of an annual check-up. In the younger age group, older and female participants tended to get an annual check-up more than their male counterparts. Previous studies report that women visit their primary care clinic and use preventive care services more often than men $[8,41]$. Such behaviors might be rooted in traditional women's roles and responsibility in managing a family's health [42] and men's lack of help-seeking behavior. Men tend to feel weak and vulnerable in helpseeking situations and viewing health symptoms as minor or insignificant $[43,44]$.

The current study indicated that health literacy is an important enabling factor of annual check-ups [45]. Participants with higher health literacy were more likely to obtain check-ups [45] and cancer screening rates [46, 47]. This study found that three different items of health 
Table 2 Logistic Regression on Physical Check-Ups by Age Groups in the United States, the 2017 US Health Information National Trends Survey

\begin{tabular}{|c|c|c|c|c|c|}
\hline \multicolumn{2}{|l|}{ Variables } & \multicolumn{2}{|c|}{ Age between 18 and 59 (Model 1) } & \multicolumn{2}{|c|}{ Age over 60 (Model 2) } \\
\hline & & OR & $95 \% \mathrm{Cl}$ & OR & $95 \% \mathrm{Cl}$ \\
\hline \multirow[t]{4}{*}{ Predisposing factors } & Age & $1.016^{* *}$ & $1.004,1.029$ & 1.008 & $0.988,1.029$ \\
\hline & Gender(ref=male) & $1.377^{* *}$ & $1.084,1.751$ & 1.242 & $0.912,1.691$ \\
\hline & Income & 0.972 & $0.915,1.032$ & 1.061 & $0.976,1.154$ \\
\hline & Urban(ref=rural) & 1.092 & $0.755,1.578$ & 0.782 & $0.504,1.214$ \\
\hline \multirow[t]{8}{*}{ Enabling factors } & A lot of Effort to get the information $(\mathrm{HL})$ & 0.945 & $0.768,1.162$ & 1.009 & $0.769,1.323$ \\
\hline & Frustrated during search for the information $(\mathrm{HL})$ & $0.758^{* *}$ & $0.617,0.933$ & 0.835 & $0.629,1.108$ \\
\hline & Concerned about the quality of the information( $\mathrm{HL})$ & 1.029 & $0.878,1.205$ & 1.017 & $0.809,1.278$ \\
\hline & Information you found was hard to understand $(\mathrm{HL})$ & 1.225 & $0.997,1.504$ & $1.428^{*}$ & $1.069,1.909$ \\
\hline & Confident Get Health Information (HL) & $1.154^{*}$ & $1.000,1.332$ & 1.183 & $0.985,1.420$ \\
\hline & Education & 1.071 & $0.981,1.170$ & 0.980 & $0.882,1.089$ \\
\hline & Health Insurance & $2.576^{* * *}$ & $1.612,4.118$ & $2.341^{*}$ & $1.024,5.352$ \\
\hline & Primary doctor & $2.636^{* * *}$ & $2.065,3.363$ & $2.361^{* * *}$ & $1.658,3.363$ \\
\hline \multirow[t]{5}{*}{ Need factors } & Health Status & 1.017 & $0.879,1.177$ & 0.992 & $0.826,1.193$ \\
\hline & Chronic Disease & $1.435^{* * *}$ & $1.235,1.668$ & $1.438^{* * *}$ & $1.228,1.685$ \\
\hline & Depression & 0.974 & $0.933,1.018$ & 0.947 & $0.889,1.010$ \\
\hline & Personal history of cancer & 0.857 & $0.542,1.353$ & 0.999 & $0.694,1.439$ \\
\hline & Family history of cancer & 0.963 & $0.741,1.251$ & 0.787 & $0.543,1.140$ \\
\hline \multicolumn{2}{|l|}{ Number of observations } & 1,465 & & 1,681 & \\
\hline \multicolumn{2}{|l|}{ Pseudo $R^{2}$} & 0.104 & & 0.07 & \\
\hline \multicolumn{2}{|l|}{ Log Likelihood Rate Test } & 199.07 & & 84.01 & \\
\hline
\end{tabular}

Note: ${ }^{*} p<.05 ;{ }^{* *} p<.01,{ }^{* * *} p<.001$

literacy predicted annual check-up in both age groups. For the younger group, feelings of frustration when searching for information negatively influenced uptake of annual check-ups; however, most older adults indicated that difficulty in understanding information was positively associated with annual check-ups. It seems that younger adults who experienced frustration while searching for information, did not want to seek medical guidance from providers receive check-ups. In contrast, difficulty understanding health information for the older age group, could potentially be the motivator in pursuing physical check-ups to ask their health care providers for the meaning and accuracy of health information. As a first step toward promoting routine check-ups, policy interventions improving health literacy that differ by age groups are required. Through this, it can be expected to enhance the check-ups rate of both age groups.

Although both groups expressed health information challenges, whether obtaining or understanding, study results indicated that annual health check-ups were positively associated with confidence in getting health information in the younger age group. Confidence in obtaining health information can stem from having reliable sources of information via the web, social media, friends, and a primary care doctor to provide more information to the people, and knowledge allows the transition to improved regular check-up behavior. These reliable sources of information also impacted health literacy levels among participants of the 2003 National Assessment of Adult Literacy [48]. Participants with proficient levels of health literacy relied on the internet or personal contacts, such as health care professionals, to answer health-related questions, those with basic or intermediate health literacy levels relied on newspapers or magazine, and below basic health literacy, individuals gathered their healthcare information mainly from either the radio or television [48].

Other enabling factors associated with annual checkup were health insurance coverage and a primary doctor for both groups. Study participants who had health insurance and a primary doctor were more likely to get annual check-ups than those who did not have either. This finding is not surprising given that health insurance and having a primary doctor are key factors in accessing health care and utilizing preventive health care. A previous study also indicated that persons who had health insurance were more likely to obtain check-ups [49]. On the other hand, the imporatance of health 
literacy is significant, even for persons with neither health insurance nor a primary doctor.

Lastly, Chronic disease was the most powerful predictor of annual check-ups for both groups. The recent study also showed that persons with chronic diseases were more likely to have check-ups [49].

\section{Limitations}

While the current study findings provide insight into the association between health literacy and physical check-up, some limitations exist. Due to the study's design, a correlation could be difficult to identify between health literacy and physical check-up; however, longitudinal studies are needed to explore the causal relationship between health literacy and physical check-up. Second, the explanatory power of the identical model is low. This model could explain only $9.0 \%$ and $5.25 \%$ of the total variance between 18 and 59 years and aged over 60 years, respectively. Some other important factors may explain the variance of health check-ups among specific age groups. Third, it's crucial to consider environmental factors and personal factors when using Andersen's Behavioral Model. However, we only include living area (rural or urban) as an environmental factor since 2017 HINTS data does not provide related information. Another limitation worth noting is the outcome measure (physical check-up) was self-reported rather than clinically or behaviorally measured, which might have caused response biases.

\section{Conclusions}

Several methods to increase annual health check-up are suggested. First, many participants in our study showed frustrations in searching for health information and difficulty understanding the meaning of professionals' medical terminologies. Health care professionals have the responsibility to share healthcare information with their patients and the larger community by using the right communication strategies. Medical information should be translated into easy-to-understand language by healthcare professionals. Additionally, policies should recommend medical facilities or primary doctors to provide routine reminders via call/text/email regarding upcoming appointments as it may promote awareness and enhance health literacy to include health check-ups in the person's agenda $[39,50]$. Moreover, it is critical for health care professionals and policymakers to have different strategies for each age group to enhance health literacy. For a younger age group, providing easily accessible health information via the internet and cultivating the capacity to find health information would be crucial. The ability to obtain accurate medical information quickly and conveniently online may provide an opportunity for better-informed decision making. At the same time, for older age groups, providing education to improve understanding of health materials should be provided [51, 52]. Lastly, it is important to increase preventive medical service utilization, such as annual checkups, to prevent health deterioration. The Institute of Medicine [53] states that the individual's efforts alone have limitations in improving health literacy. Therefore, it will be necessary to understand the mutual function between the individual and the medical environment and environmental changes. Moreover, efforts to decrease the barriers in accessibility for regular health check-ups should be accompanied by bringing awareness and service to the community with notable efforts from the health care settings.

\section{Abbreviations}

HINTS: Health Information National Trends Survey

\section{Acknowledgements}

Not applicable.

\section{Authors' contributions}

Conceptualization, HYL, SYK, MHL; data curation, HYL. and SYK; formal analysis, SYK; funding acquisition, $\mathrm{HYL}$; investigation, $\mathrm{HYL}$, SYK, MHL; methodology, SYK; project administration, HYL and MHL.; resources, HYL, SYK, MHL; writing —original draft, HYL, SYK, MHL and JN; writing-review and editing, HYL, SYK, MHL and JN. All authors have read and agreed to the published version of the manuscript.

\section{Funding}

This research was funded by the Endowed Academic Research Fund from the University of Alabama School of Social Work to the First author. This work was also supported by the National Research Foundation of Korea(NRF) grant funded by the Korea government(MSIT)(No. 2019S1A5A8035642) to the Corresponding author.

\section{Availability of data and materials}

Health Information National Trends Survey is a public use dataset that is available from .

\section{Declarations}

\section{Footnotes}

The total number of respondents in each age group are different since we applied the jackknife weighting procedures.

\section{Ethics approval and consent to participate \\ This secondary analysis used public use data that does not require ethics approval.}

\section{Consent for publication:}

Not applicable.

\section{Competing interests}

Not applicable.

\section{Author details}

${ }^{1}$ School of Social Work, University of Alabama, AL, Tuscaloosa, USA. ${ }^{2}$ Dept. of Aging and Social Work, College of Nursing, Catholic University of Pusan, Busan, South Korea. ${ }^{3}$ School of Social Work, East Carolina University, Greenville, North Carolina, USA. 
Received: 20 November 2020 Accepted: 28 February 2021 Published online: 18 March 2021

\section{References}

1. Virgini V, Meindl-Fridez C, Battegay E, Zimmerli LU. Check-up examination: Recommendations in adults. Swiss Medical Weekly. 2015;145:W14075. https://doi.org/10.4414/smw.2015.14075.

2. Gorbenko K, Metcalf SA, MPhil, Mazumdar M, Crump C. Annual physical examinations and wellness visits: Translating guidelines into practice. Am J Prev Med. 2017;52(6):813-6. https://doi.org/10.1016/j.amepre.2016.12.005.

3. Centers for Disease Control and Prevention. Check-Ups are Important Family Health - CDC. 2017.

4. Labeit A, Peinemann F, Baker R. Utilisation of preventative health check-ups in the UK: findings from individual-level repeated cross-sectional data from 1992 to 2008. BMJ open. 2013;3(12).

5. O'Malley PG, Greenland P. The annual physical: Are physicians and patients telling us something? Arch Intern Med. 2005;165(12):1333-4. https://doi. org/10.1001/archinte.165.12.1333.

6. Maciosek MV, Coffield AB, Flottemesch TJ, Edwards NM, Solberg LI. Greater use of preventive services in US health care could save lives at little or no cost. Health Aff. 2010;29(9):1656-60

7. Miller NA, Kirk A, Alston B, Glos L. Effects of gender, disability, and age in the receipt of preventive services. Gerontologist. 2014;54(3):473-87. https:// doi.org/10.1093/geront/gnt012.

8. Vaidya V, Partha G, Karmakar M. Gender differences in utilization of preventive care services in the united states. Journal of Women's Health. 2012;21(2):14-45. https://doi.org/10.1089/jwh.2011.2876.

9. Abdus S, Selden TM. Preventive services for adults: How have differences across subgroups changed over the past decade? Med Care. 2013;51(11): 999-1007. https://doi.org/10.1097/MLR.0b013e3182a97bc0.

10. Jerant A, Fiscella K, Tancredi DJ, Franks P. Health insurance is associated with preventive care but not personal health behaviors. Journal of the American Board of Family Medicine: JABFM. 2013;26(6):759-67. https://doi. org/10.3122/jabfm.2013.06.130054.

11. Blewett LA. Johnson PJ, Lee B, Scal PB. When a usual source of care and usual provider matter: Adult prevention and screening services. J Gen Intern Med. 2008;23(9):1354-60. https://doi.org/10.1007/s11606-008-0659-0.

12. Caldwell JT, Ford CL, Wallace SP, Wang MC, Takahashi LM. Intersection of living in a rural versus urban area and Race/Ethnicity in explaining access to health care in the united states. Am J Public Health. 2016;106(8):1463-9. https://doi.org/10.2105/AJPH.2016.303212.

13. DeVoe SG, Roberts LL, Davis WS, Wallace-Brodeur RR. Identifying barriers to access and utilization of preventive health-care services by young adults in vermont. J Adolesc Health. 2018;62(6):674-80. https://doi.org/10.1016/j.ja dohealth.2017.12.018.

14. Yabroff KR, Short PF, Machlin S, Dowling E, Rozjabek H, Li C, Virgo KS. Access to preventive health care for cancer survivors. Am J Prev Med. 2013; 45(3):304-12. https://doi.org/10.1016/j.amepre.2013.04.021.

15. Lafata JE, Salloum RG, Fishman PA, Ritzwoller DP, O'Keeffe-Rosetti MC, Hornbrook MC. Preventive care receipt and office visit use among breast and colorectal cancer survivors relative to age- and gender-matched cancer-free controls. J Cancer Surviv. 2015;9(2):201-7. https://doi.org/10.1 007/s11764-014-0401-3.

16. Bronner K Mesters I, Weiss-Meilnik A, Geva R, Rozner G, Strul H, Kariv R. Do individuals with a family history of colorectal cancer adhere to medical recommendations for the prevention of colorectal cancer? Fam Cancer. 2013;12(4):629-37. https://doi.org/10.1007/s10689-013-9627-x.

17. Dickman SL, Himmelstein DU, Woolhandler S. Inequality and the health-care system in the USA. Lancet the. 2017;389(10077):1431-41. https://doi.org/10.1 016/50140-6736(17)30398-7.

18. Lau JS, Adams MD, Irwin SH, Ozer CE. EM. Receipt of preventive health services in young adults. J Adolesc Health. 2013;52(1):42-9. https://doi.org/1 0.1016/j.jadohealth.2012.04.017.

19. Geboers B, Brainard JS, Loke YK, Jansen CJM, Salter C, Reijneveld SA, de Winter AF. The association of health literacy with adherence in older adults, and its role in interventions: A systematic meta-review. BMC Public Health. 2015;15(1):903. https://doi.org/10.1186/s12889-015-2251-y.

20. Levy $H$, Janke A. Health literacy and access to care. Journal of Health Communication. 2016;21(sup1):43-50. https://doi.org/10.1080/10810730.201 5.1131776 .
21. Berkman ND, Sheridan SL, Donahue KE, Halpern DJ, Crotty K. Low health literacy and health outcomes: An updated systematic review. Ann Intern Med. 2011;155(2):97. https://doi.org/10.7326/0003-4819-155-2-20110719000005.

22. Carolyn B, Jamie B, Tom B, Kristin R A Multivariate Test of an Expanded Andersen Health Care Utilization Model for complementary and Alternative Medicine (CAM) Use in African Americans. The Journal of Alternative and Complementary Medicine. 2009; 15(8): 911-919. doi: 10.1089=acm.2008. 0561

23. Patrick B, Fabian E, Dorothee W Enabling and Predisposing Factors for the Utilization of Preventive Dental Health Care in Migrants and Non-Migrants in Germany. Frontiers in Public Health. 2017; 5:201. https://doi.org/10.3389/ fpubh.2017.00201.

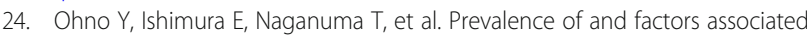
with chronic kidney disease (CKD) in Japanese subjects without notable chronic diseases, xundergoing an annual health checkup. Kidney Blood Press Res. 2012;36(1):139-148. https://doi.org/10.1159/000341490.

25. Kim SE, Kim N, Lee JY, et al. Prevalence and Risk Factors of Functional Dyspepsia in Health Check-up Population: A Nationwide Multicenter Prospective Study. J Neurogastroenterol Motil. 2018;24(4):603-613. https://doi.org/10.5056/jnm18068.

26. Amaral TLM, Amaral CA, Vasconcellos MTL, Monteiro GTR. Prevalence and factors associated to chronic kidney disease in older adults. Rev Saude Publica. 2019;53:44. https://doi.org/10.11606/S1518-8787.2019053000727.

27. Nutbeam D, McGill B, Premkumar P. Improving health literacy in community populations: a review of progress. Health Promot Int. 2018;33(5):901-11. https://doi.org/10.1093/heapro/dax015.

28. Koh HK, Rudd RE. The arc of health literacy. J Am Med Assoc. 2015:314(12): 1225-6. https://doi.org/10.1001/jama.2015.9978.

29. Andersen RM. Revisiting the behavioral model and access to medical care: Does it matter? J Health Soc Behav. 1995;36(1):1-10. https://doi.org/10.23 07/2137284.

30. Lee HY, Choi JK, Lee MH. Health literacy in an underserved immigrant population: New implications toward achieving health equity. Asian American Journal of Psychology. 2015;6(1):97-105. https://doi.org/10.1037/a0037425.

31. Zhou AQ, Lee HY, Lee RM. Who has low health literacy and does it matter for depression? Findings from aggregated and disaggregated racial/ethnic groups. Cultural Diversity Ethnic Minority Psychology. 2019;25(1):73-81. https://doi.org/10.1037/cdp0000210.

32. Holtzman CW, Shea JA, Glanz K, Jacobs LM, Gross R, Hines J, Yehia BR. Mapping patient-identified barriers and facilitators to retention in HIV care and antiretroviral therapy adherence to andersen's behavioral model. AIDS Care. 2015;27(7):817-28. https://doi.org/10.1080/09540121.2015.1009362.

33. Chertok IRA, Chertok N, Haile ZT, Chavan B. Association of youth characteristics and recent utilization of dental services in the united states. Frontiers in Pediatrics. 2018;6:104. https://doi.org/10.3389/fped.2018.00104.

34. Bradle EH, McGraw SA, Curry L, Buckser A, King KL, Kasl SV, Andersen R. Expanding the andersen model: The role of psychosocial factors in LongTerm care use. Health Serv Res. 2002;37(5):1221-42. https://doi.org/1 $0.1111 / 1475-6773.01053$

35. Wister AW, Malloy-Weir L, Rootman I, Desjardins R. Lifelong educational practices and resources in enabling health literacy among older adults. Journal of Aging Health. 2010;22(6):827-54. https://doi.org/10.1177/08982 64310373502

36. World Health. Organization(WHO): https://www.who.int/health-topics/a geing\#tab=tab_1).

37. StataCorp. Stata Statistical Software: Release 12. College Station. TX StataCorp LP; 2011.

38. Luquis R. Kensinger W. Perceptions of Health Care and Access to Preventive Services Among Young Adults. J Community Health, 2017;42(6):1204-12. https://doi.org/10.1007/s10900-017-0371-2

39. Sheffet AM, Ridlen S, Louria DB. Baseline Behavioral Assessment for the New Jersey Health Wellness Promotion Act. American Journal of Health Promotion. 2006;20(6):401-10. https://doi.org/10.4278/0890-1171-20.6.401.

40. Lee E, Lee HY, Chung S. Age Differences in Health Literacy: Do Younger Korean Adults Have a Higher Level of Health Literacy than Older Korean Adults? Health Social Work. 2017:42(3):133-42. https://doi.org/10.1093/hsw/hlx026.

41. Bertakis KD, Azari R, Callahan EJ, Robbins JA, Helms LJ. Comparison of primary care resident physicians' practice styles during initial and return patient visits. J Gen Intern Med. 1999;14(8):495-8. https://doi.org/10.1046/j.1 525-1497.1999.05068.x 
42. Oksuzyan A, Juel K, Vaupel JW, Christensen K. Men: good health and high mortality. Sex differences in health and aging. Aging clinical experimental research. 2008;20(2):91-102. https://doi.org/10.1007/BF03324754.

43. O'brien R, Hunt K, Hart G. It's caveman stuff, but that is to a certain extent how guys still operate': men's accounts of masculinity and help seeking. Soc Sci Med. 2005;61(3):503-16. https://doi.org/10.1016/j.socscimed.2004.12. 008.

44. Yousaf O, Grunfeld E, Hunter M. A systematic review of the factors associated with delays in medical and psychological help-seeking among men. Health Psychology Review. 2013;9(2):264-76. https://doi.org/10.1080/1 7437199.2013 .840954

45. Eiko G, Hirono I, Tsuyoshi O, Takahiro K. Relationship of health literacy with utilization of health-care services in a general Japanese population. Preventive Medicine Reports. 2019;14. https://doi.org/10.1016/j.pmedr.2019. 01.015.

46. Kim K, Han HR. Potential links between health literacy and cervical cancer screening behaviors: a systematic review. Psychooncology. 2016;25(2):12230. https://doi.org/10.1002/pon.3883.

47. Benjamin R, Oldach ML, Katz. Health literacy and cancer screening: A systematic review. Patient Educ Couns. 2014;94(2):149-57. https://doi.org/1 0.1016/j.pec.2013.10.001.

48. Kutner M, Greenburg E, Jin Y, Paulsen C. The Health Literacy of America's Adults: Results from the 2003 National Assessment of Adult Literacy. NCES 2006 - 483. National Center for Education Statistics. 2006.

49. Culica D, Rohrer J, Ward M, Hilsenrath P, Pomrehn P. Medical checkups: who does not get them? Am J Public Health. 2002;92(1):88-91. https://doi. org/10.2105/ajph.92.1.88.

50. Schmittdiel J, McMenamin SB, Halpin HA, Gillies RR, Bodenheimer T, Shortell SM, Casalino LP. The use of patient and physician reminders for preventive services: results from a National Study of Physician Organizations. Prev Med. 2004;39(5): 1000-6. https://doi.org/10.1016/j.ypmed.2004.04.005.

51. Edejer TT. Disseminating health information in developing countries: the role of the Internet. BMJ. 2000;321(7564):797-800. https://doi.org/10.1136/ bmj.321.7264.797.

52. Gretchen KB, Marc NE, Leo SM, Jeffrey IA, Richard LK, Michael SB, David EK, Jorge AM, Juan-Antonio P, Marielena L, Katherine EW, Hannah Y, Elizabeth AM. Health Information on the Internet: Accessibility, Quality, and Readability in English and Spanish. Journal of American Medical Association. 2001;285(20):2612-21. https://doi.org/10.1001/jama.285.20.2612.

53. Institute of Medicine. Health literacy: a prescription to end confusion. Washington. DC: National Academic Press; 2004

\section{Publisher's Note}

Springer Nature remains neutral with regard to jurisdictional claims in published maps and institutional affiliations.

Ready to submit your research? Choose BMC and benefit from:

- fast, convenient online submission

- thorough peer review by experienced researchers in your field

- rapid publication on acceptance

- support for research data, including large and complex data types

- gold Open Access which fosters wider collaboration and increased citations

- maximum visibility for your research: over $100 \mathrm{M}$ website views per year

At $\mathrm{BMC}$, research is always in progress.

Learn more biomedcentral.com/submissions 